\title{
AVALIAÇÃO DA ACESSIBILIDADE EFETIVA DO BLOCO “G” DA UNIVERSIDADE CATÓLICA DE PERNAMBUCO
}

\author{
SILVA, Verlândia do Nascimento (1); \\ BAPTISTA, Arthur Henrique Neves (2)
}

(1) Universidade Católica de Pernambuco, Graduanda em Arquitetura e Urbanismo

e-mail:verlandia21nascimento@gmail.com

(2) Universidade Católica de Pernambuco, Doutor em Desenvolvimento Urbano

e-mail: arthurbap@gmail.com

\begin{abstract}
RESUMO
Este trabalho contempla o estudo de Acessibilidade Efetiva tendo como objeto o Bloco "G" da Universidade Católica de Pernambuco. Foram aplicados técnicas e procedimentos propostos pela Teoria da Acessibilidade Efetiva com o intuito de obter uma avaliação preliminar das condições de acesso físico à edificação.
\end{abstract}

Palavras chave: Acessibilidade Efetiva; Ergonomia; Desenho Universal.

\begin{abstract}
This work contemplates the study of Effective Accessibility with the object "Block" G of the Universidade Católica de Pernambuco. Techniques and procedures proposed by the Theory of Effective Accessibility were applied in order to obtain a preliminary assessment of the conditions of physical access to the building.
\end{abstract}

Keywords: Effective Accessibility; Ergonomics; Universal Design.

\section{INTRODUÇÃO}

O Bloco "G" é a principal edificação da Universidade Católica de Pernambuco (UNICAP). Está localizado em uma área privilegiada do centro da cidade, e é desfrutado diariamente por um número significativo de pessoas. Não apenas por alunos, professores e funcionários, mas também, por transeuntes que optam por acessar o local seja para utilização de seus serviços ou como espaço de passagem para seus destinos ou outras áreas da UNICAP.

Estas pessoas possuem qualidades, funções e limitações diferentes, trazendo a necessidade de se existir um espaço que possa ser acessível por todos de forma igualitária, independente de suas limitações físicas, sensoriais ou cognitivas. Com este intuito, o trabalho busca a verificação da Acessibilidade Efetiva do bloco em estudo, para entender em uma abordagem ergonômica o nível de acessibilidade e buscar possíveis soluções visando um Desenho Universal. 


\section{(x) $^{\text {enex }}$}

\section{CONCEITUAÇÃO TEÓRICA}

A Acessibilidade Efetiva pode ser compreendida como resultado das interações entre as aptidões de um elemento acessante, as exigências das atividades realizadas, a configuração do elemento acessado e o contexto circunstancial em que este se encontra, configurando um SATA - Sistema Acessante - Tarefa - Acessado. A Teoria é baseada em três pilares: Ergonomia, Desenho Universal e na Classificação Internacional de Funcionalidade Incapacidade e Saúde, que defende que o desempenho de uma pessoa só pode ser analisado se for considerando a influência de fatores ambientais, que podem ser barreiras ou facilitadores (BAPTISTA, 2010)

\section{PROCEDIMENTOS METODOLÓGICOS}

Nesta etapa do desenvolvimento do trabalho, foi realizada uma apreciação subjetiva pelo próprio pesquisador considerando três tipos de Sistema Acessante (Usuários/Pessoa), e dois tipos de tarefas associados a um contexto específico, são eles:

- Acessante 01 - Pessoa sem nenhum tipo de limitação física (grupo de controle para comparações);

- Acessante 02 - Pessoa com restrição físico-motora, usuário de cadeira de rodas;

- Acessante 03 - Pessoa com restrição sensorial - visual, usuária de bastão de rastreamento;

- Contexto positivo - Utilização a passeio (dia sem muita movimentação e tarefas amenas a passeio - ênfase nas barreiras fixas);

- Contexto negativo - Utilização a trabalho (dia/horário de grande movimentação e tarefas realizadas apressadamente - barreiras fixas e móveis).

\section{LEVANTAMENTO E CONSIDERAÇÕES}

O bloco em estudo (Bloco G) é um dos maiores blocos da instituição e o que comporta o maior número de alunos. Para a maioria dos transeuntes que não possuem limitações físicas (Ambulantes) quase não encontram dificuldades para acessar o local. A pessoa cadeirante, por outro lado, pode vir a obter dificuldades com algumas barreiras físicas existentes. A pessoa cega, dentre todas, é definitivamente o mais prejudicado, tendo em vista que, apesar de não haver grandes barreiras físicas, não foram encontrados grandes facilitadores táteis ou sonoros que suprissem a sua restrição visual dificultando a passagem ou permanecia no local (ver quadro 01).

As portas de algumas salas estão obstruídas por papéis, o que impede a visibilidade, e as aberturas possuem 1,40 m de altura, o que mesmo que não houvesse obstrução ainda não seria possível a visibilidade de cadeirantes ou pessoas com baixa estatura. Não foi encontrado nenhuma identificação em braile em nenhuma das portas (Banheiros, secretaria ou salas de aula). O corredor possui 2,15 m, o que pela NBR 9050/2015 seria uma boa distância, até mesmo para duas cadeiras de rodas (Que segundo a norma seria de $1,50 \mathrm{~m}$ a $1,80 \mathrm{~m}$ ), mas em dias de e horários de muita movimentação as lixeiras, os bebedouros e os bancos podem vir a se tornar possíveis barreiras (ver figuras do quadro 01). A partir da análise no local e dos conceitos de Acessibilidade Efetiva, o trabalho visa um entendimento das problemáticas e suas possíveis soluções. Nas próximas etapas, o processo de avaliação será aperfeiçoado para um diagnóstico mais preciso. 
Quadro 01- Análise da Acessibilidade Efetiva. Fonte: Autores (2018)
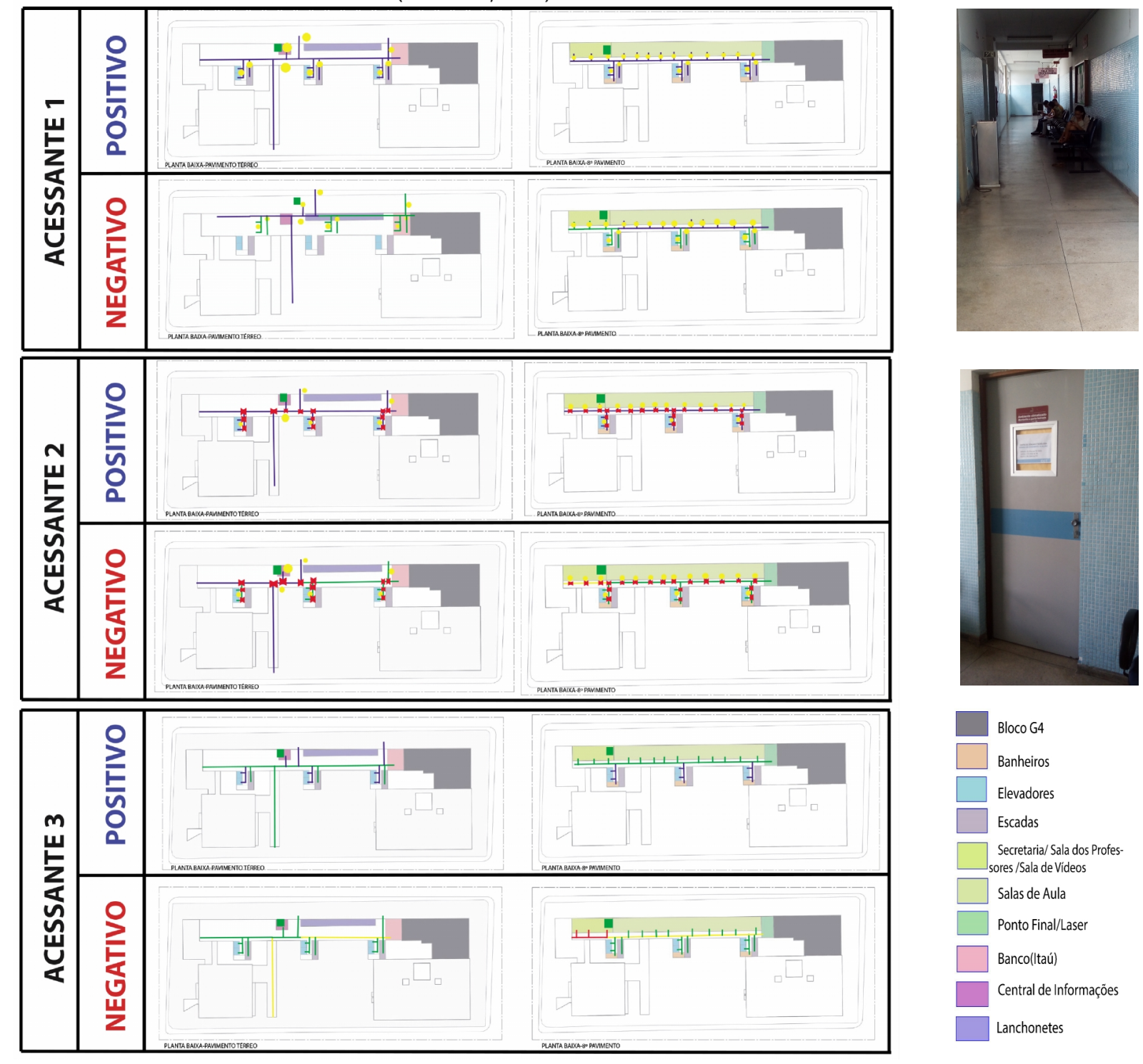

\begin{tabular}{|c|c|c|c|c|c|c|c|}
\hline $\begin{array}{c}\text { Faixas do } \\
\text { Espectro de } \\
\text { Acessibilidade }\end{array}$ & $\begin{array}{l}\text { Ultra- } \\
\text { violeta }\end{array}$ & Azul & Verde & Amarela & Laranja & Vermelha & $\begin{array}{c}\begin{array}{c}\text { Infra- } \\
\text { vermelha }\end{array} \\
\ldots . . . . .\end{array}$ \\
\hline $\begin{array}{l}\text { Acessibilidade } \\
\text { Efetiva (x) }\end{array}$ & $x>1,00$ & $0,80<x \leq 1,00$ & $0,60<x \leq 0,80$ & $0,40<x \leq 0,60$ & $0,20<x \leq 0,40$ & $0<x \leq 0,20$ & $x \leq 0$ \\
\hline & Acesso & \multicolumn{5}{|c|}{ Acesso possivel - intermediário } & \multirow{3}{*}{$\begin{array}{c}\text { Acesso } \\
\text { nulo }\end{array}$} \\
\hline Segurança & pleno com & Adequada & Boa & Razoável & Pouca & Sem & \\
\hline Conforto & excessos & Adequado & Bom & Razoável & Pouco & Sem & \\
\hline
\end{tabular}

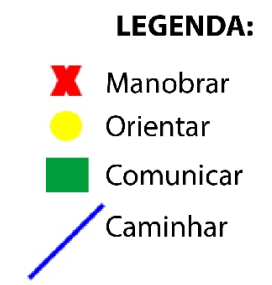

\section{REFERÊNCIAS BIBLIOGRÁFICAS}

ASSOCIAÇÃO BRASILEIRA DE NORMAS TÉCNICAS - ABNT. NBR 9050; Acessibilidade de pessoas portadoras de deficiências a edificações, espaço, mobiliário e equipamentos urbanos. Rio de Janeiro: ABNT, 2015

BAPTISTA, A. H. N. Proposição da Teoria da Acessibilidade Efetiva com plano de verificação para estruturas de circulação de pedestre. Tese (Doutorado em Desenvolvimento Urbano). Universidade Federal de Pernambuco, Recife: o autor, 2010. 